\title{
DESAFIOS DA GESTÃO NAS ESCOLAS DAS ÁGUAS
}

\author{
DESAFIOS DE LA GESTIÓN EN LAS ESCUELAS DE LAS AGUAS
}

CHALLENGES OF MANAGEMENT IN THE SCHOOLS OF WATERS

\author{
Washington Cesar Shoiti NOZU ${ }^{1}$ \\ Andressa Santos REBELO ${ }^{2}$ \\ Mônica de Carvalho Magalhães KASSAR ${ }^{3}$
}

RESUMO: Gestão escolar relaciona-se tanto às questões da administração geral, quanto a aspectos pedagógicos. Este artigo objetiva apresentar a atuação da gestão nas "Escolas das Águas", localizadas no Pantanal de Mato Grosso do Sul. Para seu desenvolvimento, foi adotada a perspectiva qualitativa, com levantamento de documentação, observação e realização de entrevistas com as gestoras dessas escolas. Os dados foram sistematizados e organizados em dois eixos: a) Caracterização e Funcionamento das Escolas das Águas; e b) Proposta Curricular e Acompanhamento do Trabalho Pedagógico. Verificou-se que a autonomia necessária para a realização do trabalho de gestão encontra entraves pela insuficiência de condições materiais para um trabalho mais próximo à comunidade.

PALAVRAS-CHAVE: Escolas das águas. Gestão escolar. Pantanal de Mato Grosso do Sul. Diversidade.

RESUMEN: La gestión escolar se relaciona con cuestiones de administración general y con aspectos pedagógicos. Este artículo tiene como objetivo presentar prácticas de gestión en las "Escuelas de Aguas", ubicadas en el Pantanal de Mato Grosso do Sul (Brasil). Para su desarrollo, se adoptó la perspectiva cualitativa, con el estudio de la documentación, observaciones del trabajo de gestión y entrevistas con las gestoras de estas escuelas. Los datos fueron sistematizados y organizados en dos ejes: a) Caracterización y funcionamiento de las Escuelas de Aguas; y b) Propuesta curricular y seguimiento del trabajo pedagógico. Se encontró que la autonomía necesaria para llevar a cabo el trabajo de gestión se ve obstaculizada por las condiciones materiales insuficientes para trabajar más cerca de la comunidad.

PALABRAS CLAVE: Escuelas de la Aguas. Gestión escolar. Pantanal de Mato Grosso do Sul. Diversidad.

\footnotetext{
${ }^{1}$ Universidade Federal da Grande Dourados (UFGD), Dourados - MS - Brasil. Docente Permanente do Programa de Pós-Graduação em Educação e do Programa de Pós-Graduação em Fronteiras e Direitos Humanos. Doutorado em Educação (UFGD). ORCID: https://orcid.org/0000-0003-1942-0390. E-mail: wcsn1984@yahoo.com.br

${ }^{2}$ Universidade Federal de Mato Grosso do Sul (UFMS), Corumbá - MS - Brasil. Docente Permanente do Programa de Pós-Graduação em Educação. Doutorado em Educação (UFMS). ORCID: https://orcid.org/00000003-1873-5622. E-mail: andressarbl@gmail.com

${ }^{3}$ Universidade Federal de Mato Grosso do Sul (UFMS), Corumbá - MS - Brasil. Docente Permanente do Programa de Pós-Graduação em Educação. Doutorado em Educação (UNICAMP). ORCID: https://orcid.org/0000-0001-5577-6269. E-mail: monica.kassar@gmail.com
}

RPGE- Revista on line de Política e Gestão Educacional, Araraquara, v. 24, n. esp. 2, p. 1054-1067, set. $2020 . \quad$ e-ISSN:1519-9029 DOI: https://doi.org/10.22633/rpge.v24iesp2.14331 
ABSTRACT: School management is related to both general administration issues and pedagogical aspects. This article aims to present the work of school management in the "Schools of Waters" (School in riverside areas), located in the Pantanal of Mato Grosso do Sul (Brazil). For its development, the qualitative perspective was adopted, with a study of documentation, observation and interviews with the school's managers. The data were systematized and organized in two topics: a) Characterization and Functioning of the Schools of Waters; and b) Curricular Proposal and Monitoring of Pedagogical Work. It was found that the necessary autonomy to carry out the management work is hampered by the insufficient material conditions for work closer to the community.

KEYWORDS: Schools of waters. School management. Pantanal of Mato Grosso do Sul. Diversity.

\section{Introdução}

A gestão escolar vem ganhando foco nas pesquisas educacionais sob diferentes perspectivas; dentre elas, há a que se preocupa em entender relações entre gestão e diferenças de desempenho entre as escolas, a que pretende descrever peculiaridades da organização escolar de uma determinada realidade, a que se debruça sobre as relações de poder institucional, entre outras. A variedade de focos e temáticas foi registrada em revisão de literatura sobre o conceito de gestão escolar empreendida por Oliveira e Vasques-Menezes (2018), que verificaram que a produção na área migrou de abordagens com focos nas relações administrativas para as de conteúdos mais pedagógicos e políticos. No texto, as autoras apontam para uma lacuna relativa a pesquisas que abordem "o cotidiano da gestão e dos sujeitos que compõem a comunidade escolar" (p. 878). Embora a pesquisa que fornece elementos para a elaboração deste trabalho não tenha características de estudos de cotidiano, de certa forma este artigo identifica-se com essa perspectiva, na medida em que evidencia desafios da gestão escolar e aspectos da construção de práticas gestoras em uma localidade peculiar.

A peculiaridade refere-se às condições fisiográficas em que estão localizadas escolas conhecidas como Escolas das Águas. Estas escolas encontram-se em locais de difícil acesso no Pantanal corumbaense, em Mato Grosso do Sul, e a permanência nessas localidades é influenciada pelos ciclos de cheias e secas do rio Paraguai e seu afluentes. No período de cheia, alguns ribeirinhos se deslocam para casa de parentes no perímetro urbano de Corumbá e outros acampam em barracas nos locais mais altos e não alagados (CORUMBÁ, 2015).

Diante desse cenário, este artigo tem como objetivo apresentar a atuação da gestão administrativo-pedagógica das Escolas das Águas, com ênfase na diversidade de situações e de 
desafios enfrentados para a organização escolar nas comunidades ribeirinhas do Pantanal corumbaense.

\section{Procedimentos metodológicos}

O percurso investigativo foi orientado pela abordagem qualitativa, com vistas à compreensão do fenômeno educativo em um contexto específico. Conforme Richardson (2017, p. 67), nessa abordagem:

O processo de pesquisa envolve as questões e os procedimentos que emergem, os dados tipicamente coletados no ambiente do participante, a análise dos dados indutivamente construída a partir das particularidades para os temas gerais e as interpretações feitas pelo pesquisador acerca do significado dos dados.

As Escolas das Águas estão ligadas administrativamente à Secretaria Municipal de Educação de Corumbá (SEMED) e, para a realização do trabalho de pesquisa, obtivemos a autorização expressa da administração executiva, bem como sua aprovação junto à Plataforma Brasil, com Certificado de Apresentação para Apreciação Ética - CAAE: 25693219.1.0000.5160.

A coleta de dados foi realizada na sede administrativo-pedagógica das Escolas das Águas, localizada no perímetro urbano do município, por meio de: a) estudo de documentos; b) observação do cotidiano de trabalho da equipe gestora, registrada em diário de campo; c) entrevistas semiestruturadas com a Diretora e as três Coordenadoras Pedagógicas (doravante identificadas como CP1, CP2 e CP3), a partir de um roteiro com 14 perguntas e com gravação de áudio.

O Quadro 1 apresenta o perfil das participantes da pesquisa.

Quadro 1 - Formação e Experiência da Equipe Gestora das Escolas das Águas

\begin{tabular}{|c|c|c|c|}
\hline $\begin{array}{c}\text { Equipe } \\
\text { Gestora }\end{array}$ & Graduação & Pós-Graduação & $\begin{array}{c}\text { Tempo de Gestão } \\
\text { em Escolas das } \\
\text { Águas }\end{array}$ \\
\hline Diretora & Pedagogia & Especialização em Administração Escolar & 15 anos \\
\hline CP1 & $\begin{array}{c}\text { Pedagogia e } \\
\text { História }\end{array}$ & $\begin{array}{c}\text { Especialização em Gestão Escolar e em } \\
\text { Educação, Pobreza e Desigualdade Social } \\
\text { Mestrado em Educação Social }\end{array}$ & 22 anos \\
\hline CP2 & Pedagogia & $\begin{array}{c}\text { Especialização em Metodologia do } \\
\text { Ensino Fundamental e em Arte Educação }\end{array}$ & 3 anos \\
\hline CP3 & Letras & Especialização em Língua Portuguesa & 3 anos \\
\hline
\end{tabular}

Fonte: elaboração própria

RPGE- Revista on line de Política e Gestão Educacional, Araraquara, v. 24, n. esp. 2, p. 1054-1067, set. 2020. e-ISSN:1519-9029 DOI: https://doi.org/10.22633/rpge.v24iesp2.14331 
Neste artigo, utilizamos dados coletados no final do ano de 2019. As informações advindas de observação foram grafadas neste texto como registro de diário de campo. Por sua vez, as informações oriundas de entrevistas foram transcritas e passaram por processo de textualização, com supressão de expressões típicas da linguagem oral, com autorização das participantes.

Os dados foram sistematizados e organizados em dois eixos analíticos, a saber: a) Caracterização e Funcionamento das Escolas das Águas; e b) Proposta Curricular e Acompanhamento do Trabalho Pedagógico.

\section{As Escolas das Águas: entre as peculiaridades da região e a normatização administrativa}

As escolas foco deste artigo estão localizadas no município de Corumbá, na região do Pantanal Sul-mato-grossense que, conforme dados do último Censo Demográfico, possui 103.703 habitantes ${ }^{4}$.

Relativamente à escolaridade da população, a Secretaria Municipal de Educação (SEMED) responsabiliza-se prioritariamente pela Educação Infantil e pelo Ensino Fundamental, sendo que as matrículas se concentram nos anos iniciais do ensino obrigatório (INEP, 2019). Dados recentes informam que em 2019 o município apresentou 25.459 matrículas na Educação Básica, considerando as 63 escolas das redes municipal, estadual, federal e privada. Do total, 14.360 delas estavam sob dependência municipal, entre seus 35 estabelecimentos.

A rede municipal de ensino de Corumbá/MS apresenta características geográficas e históricas peculiares, "com escolas funcionando em prédios históricos, onde a acessibilidade arquitetônica é dificultada, e outras situadas muito distantes do polo urbano, com acesso exclusivo por navegação" (KASSAR et al., 2018, p. 302). Dentre essas escolas, estão as Escolas das Águas que, em 2019, agrupavam cinco unidades de ensino definidas como polos e quatro como extensões, distribuídas, de acordo com classificação da administração municipal (CORUMBÁ, 2015), nas regiões do Baixo, do Médio e do Alto Pantanal:

${ }^{4}$ Disponível em: https://cidades.ibge.gov.br/brasil/ms/corumba/panorama. Acesso em: 12 jun. 2020. 
Quadro 1 - Escolas das Águas do Pantanal Corumbaense (2019)

\begin{tabular}{|c|c|c|}
\hline Região & Polo & Extensão \\
\hline Baixo Pantanal & Porto Esperança & - \\
\hline Médio Pantanal & Santa Aurélia & São João \\
\cline { 2 - 3 } & Sebastião Rolon & Nazaré \\
\hline \multirow{2}{*}{ Alto Pantanal } & Paraguai Mirim & Jatobazinho \\
\cline { 2 - 3 } & São Lourenço & Santa Mônica \\
\hline
\end{tabular}

Fonte: elaboração própria

Tomando como referência o Porto Geral de Corumbá às margens do rio Paraguai, no perímetro urbano, aproximadamente, temos as seguintes distâncias: Baixo Pantanal - 280 km; Médio Pantanal - 180 km; e Alto Pantanal - 320 km (CORUMBÁ, 2015).

A distribuição de matrículas nas Escolas das Águas, em setembro de 2019, deu-se com: 21 matrículas em Porto Esperança; 11 em Santa Aurélia; 34 em São João; 22 em Sebastião Rolon; 41 em Nazaré; 46 em Paraguai Mirim; 48 em Jatobazinho; 20 em São Lourenço; e 50 em Santa Mônica. Ao todo, as Escolas das Águas registraram 293 matrículas, representando aproximadamente $2 \%$ do conjunto de matrículas da rede municipal de ensino, no mesmo ano.

Embora integradas sob a denominação "das Águas”, nem todas as unidades de ensino fixam-se às margens dos rios (MELO, 2017). Particularmente, a região onde estão as escolas no Médio Pantanal (Santa Aurélia, São João, Sebastião Rolon e Nazaré) sofreu uma grave crise hídrica no ano de 2019, em decorrência da seca do rio Taquari. Assim, ainda que as condições materiais de existência dos alunos e seus familiares sejam similares - renda familiar baixa e acesso precário aos direitos fundamentais (ZERLOTTI, 2014; MELO, 2017; OLIVEIRA, 2018; RIOS, 2020), as Escolas das Águas têm como marca distintiva a heterogeneidade: de naturezas jurídicas, calendários escolares, meios de transportes, estruturas físicas, regimes de funcionamento. Das nove unidades de ensino, duas são regidas por parcerias público-privadas: Jatobazinho e Santa Mônica. A primeira resulta de parceria entre a Prefeitura Municipal e o Instituto Acaia; a segunda entre a Prefeitura Municipal e o Instituto Rural Escola das Águas (MELO, 2017; OLIVEIRA; 2018; RIOS, 2020).

O "barco escola" e o "trator com carretinha" são os meios de transportes públicos, de uso diário, para os alunos que residem nas localidades mais próximas às escolas; há casos de alunos que vão caminhando ou a cavalo até as unidades de ensino, além daqueles em que os familiares fazem o transporte por meio das "voadeiras" (pequenas embarcações movidas a motor).

A estrutura física das unidades, de um modo geral, é simples com duas ou três salas de aulas, com energia elétrica e internet limitadas. As escolas Jatobazinho e Santa Mônica (de 
parcerias público-privadas) possuem estrutura física qualitativamente diferenciada em relação às demais (MELO, 2017; RIOS, 2020).

\section{Caracterização e funcionamento das Escolas das Águas}

Até os anos finais da década de 1990, as escolas localizadas nas comunidades ribeirinhas eram administradas no conjunto das instituições de ensino localizadas no meio rural de Corumbá. Conforme a Diretora das Escolas das Águas nos relatou, “antes era só uma diretoria que atendia todas as escolas, do campo, ribeirinhas, de assentamentos, tudo. Aí depois foi desmembrada".

As escolas foram, processualmente, sendo (re)configuradas visando uma atenção específica às diferentes populações camponesas do município. Segundo a CP1, as escolas “foram (re)divididas a cada governo, cada secretaria, cada pasta que entrava lá fazia uma nova divisão, um novo ajuste e aí acaba na formatação que existe hoje de Escolas das Águas". De acordo com as gestoras, a Escola Municipal Rural de Porto Esperança constituiu-se como o primeiro polo para atendimentos a outras unidades de ensino em regiões das águas, chamadas de extensões. Para Oliveira (2018, p. 48), “o termo extensão é utilizado para se referir às escolas que funcionam em unidades separadas. Elas têm uma estrutura física de escola independente, [...] porém, nos documentos municipais estão vinculadas a uma escola polo”. A ampliação da oferta de extensões, sobretudo na região do Alto Pantanal, deveu-se a ação estratégica de enfrentamento ao trabalho infantil nas comunidades ribeirinhas (ABREU, 2018).

Rios (2020) informa que a nomenclatura Escolas das Águas irá aparecer em alguns documentos administrativos a partir de 1997. Zerlotti (2014) e Melo (2017) sinalizam que o termo vem sendo empregado informalmente nas ações educacionais locais. Contudo, encontramos algumas pistas no Plano Municipal de Educação de Corumbá (2015-2025) que, embora não apresente uma definição, faz menção à educação dos povos das águas, inclusive com currículos e propostas específicas, considerando suas particularidades socioculturais (CORUMBÁ, 2015).

De todo modo, a equipe gestora nos esclareceu que uma resolução municipal se encontra em tramitação com o intuito de dispor sobre os princípios básicos da educação nas Escolas do Campo e das Águas de Corumbá. Nessa sistemática é válido salientar que, atualmente, embora possua equipe administrativo-pedagógica própria na área urbana do município, as Escolas das Águas estão vinculadas ao Núcleo de Educação do Campo da SEMED. 
A oferta de escolarização concentra-se nos anos iniciais do Ensino Fundamental e com predomínio de turmas multisseriadas. Ainda assim, há várias especificidades entre as unidades de ensino. Em 2019, de acordo com a demanda, algumas ofereceram também a etapa da Educação Infantil (Pré-Escola) - Porto Esperança, São João, Jatobazinho e Paraguai Mirim - e os anos finais do Ensino Fundamental - Porto Esperança, Santa Aurélia, São João, Sebastião Rolon, Nazaré, Paraguai Mirim e São Lourenço. No que diz respeito à formação de turmas, com exceção da Jatobazinho que se organizou por seriação e Santa Mônica por seriação/bisseriação, nas demais unidades de ensino a enturmação se deu por multissérie.

As demandas e características ambientais também levaram a outras decisões da gestão, como a reorganização do calendário escolar. Em 2019, havia seis calendários diferentes para as nove unidades de ensino. Segundo o relato da Diretora: "com o decorrer do tempo, pela natureza e pelo clima, nós começamos a trabalhar com calendário adaptado em quase todas as escolas. Porque às vezes uma parava para reforma. Às vezes, por conta de uma enchente, parava em uma e em outra não".

O regime de funcionamento das Escolas das Águas, segundo a sua equipe gestora, também se altera com frequência, a depender da condição natural e da demanda discente. Nesse sentido, conforme a Diretora, as escolas podem ter "regime regular (com quatro horas aulas), jornada ampliada (com cinco horas aulas) e integral (com oito horas aulas)". No ano de 2019, com exceção de Santa Aurélia e de São João, que funcionaram em regime regular, as outras unidades de ensino trabalharam em período integral.

No final do ano de 2019, a equipe gestora também estudava a possibilidade de adoção de regime de alternância - tempo escola e tempo comunidade - nas Escolas das Águas (registro de diário de campo). $\mathrm{O}$ relato da Diretora apresentou algumas justificativas:

Nós estamos pensando em um regime de alternância, justamente por conta do clima de Corumbá, por conta de enchente e seca, porque passamos por esses dois momentos. É muito difícil, quando a cheia é demais, o barco não chega, e as familias ribeirinhas saem da comunidade para vir para cidade, porque as casas delas ficam alagadas. E às vezes a cheia é muito forte e até na escola chega, então a gente tem que parar realmente a aula. Na seca é muito seco, então a gente passa por falta de água, principalmente na região do Taquari. O rio Taquari está secando e a água vem de poço, e quando é muito seco os poços também têm a tendência de secar. Então, por essa realidade, estamos com esse estudo: fazer uma experiência piloto pelo menos em duas escolas para ver se conseguimos realizar esse regime de alternância.

Diante das longas distâncias entre os locais de moradia e as unidades de ensino de muitos alunos, havia oferta de alojamentos estudantis nas próprias dependências físicas de 
Nazaré, Jatobazinho, Paraguai Mirim, São Lourenço e Santa Mônica. Nas três primeiras, o internato se dava durante a semana e nas duas últimas, no decurso do bimestre.

Em 2019, atuavam de três a quatro professores em cada unidade de ensino; em Paraguai Mirim e Jatobazinho esse número era superior, com cinco e seis docentes, respectivamente. Além de professores, as escolas dispunham de merendeiras, assistentes de serviços gerais, piloteiros e tratoristas, e de monitores de alojamentos. Estes profissionais, hegemonicamente, residiam no perímetro urbano de Corumbá, permanecendo alojados nas dependências das escolas durante o período letivo, com vindas programadas para a cidade, comumente, nos interstícios dos bimestres.

\section{Proposta curricular e acompanhamento do trabalho pedagógico}

Em 2019, havia um Projeto Político Pedagógico (PPP) da Escola Municipal Rural de Educação Integral Polo Porto Esperança e Extensões, tomado como referência para orientar as ações em todas as unidades de ensino. Este documento, datado de 2017, é constituído pelas seções: Apresentação; I. Gestão Escolar; II. Coordenação Pedagógica; III. Identificação; IV. Histórico da Escola; V. Dados de Identificação; VI. Da Visão aos Objetivos; VII. Organização e Funcionamento das Etapas Oferecidas; VIII. Organização Curricular; IX. Considerações sobre o Currículo; X. Estratégias de Ensino para Educação Básica; XI. Avaliação Escolar; XII. Espaço Físico; XIII. Perfil do Corpo Docente e Técnico Administrativo; XIV. Da Formação em Serviço; XV. Da Avaliação Institucional; XVI. Atendimento aos Alunos com Necessidades Especiais; XVII. Do Regime Escolar; XVIII. Projetos; XIX. Ações da Escola; Referências; Anexos (CORUMBÁ, 2017). Nas seções III. Identificação, IV. Histórico da Escola e V. Dados de Identificação do PPP são apresentadas informações sobre as cinco escolas polos e suas extensões.

Segundo a CP3, "quando nos reunimos para fazer o Projeto Político Pedagógico, buscamos ver a realidade de cada uma das escolas, de trabalhar em cima dessa realidade. Nós buscamos atender as especificidades dos nossos alunos ribeirinhos". Em razão da alteração de regime de funcionamento de unidades de ensino, a Diretora sinalizou um movimento de atualização:

[...] por conta da matriz curricular que está mudando, por conta de escola que era regular e passou para educação integral, escola que era regular e passou para jornada ampliada. Então por todos esses motivos está acontecendo a reformulação do Projeto Político Pedagógico. 
Destacam-se aqui aspectos enfrentados pela gestão, na organização das escolas, tendo em vista o constante movimento das condições naturais às quais estão submetidas. Tanto a Educação Infantil quanto o Ensino Fundamental das Escolas das Águas previam a carga horária de 1600 horas anuais (CORUMBÁ, 2017). Os conteúdos na Educação Infantil estavam organizados pelos eixos: “O Eu, o Outro e o Nós; Escuta, fala, pensamento e imaginação; Espaços, tempos, quantidades, relações e transformações; Corpo, gestos e movimentos; Traços, sons, cores e formas; Língua Estrangeira Moderna; Atividades Eletivas" (CORUMBÁ, 2017, p. 8). Por seu turno, o Ensino Fundamental organizava o currículo com uma base comum e outra diversificada (CORUMBÁ, 2017; MELO, 2017), por meio dos componentes: Arte; Atividades Artísticas e Culturais; Ciências; Comunicação e Mídias; Educação Física; Formação Cidadã; Geografia; História; Iniciação Esportiva; Língua Estrangeira Moderna (Inglês); Língua Portuguesa; Matemática; Orientações para Estudo, Pesquisa e Oralidade.

A pesquisa de Zerlotti (2014, p. 116), desenvolvida em uma unidade de ensino do Alto Pantanal, evidenciou "que os saberes dos alunos eram contemplados em apenas algumas atividades pontuais e que não estavam representados nos livros didáticos utilizados". Melo (2017, p. 121), em estudo realizado em outra unidade de ensino também no Alto Pantanal, informou que "no currículo da escola não há nenhuma referência à cultura pantaneira, tampouco nas falas dos professores que participaram do estudo, dessa maneira é possível afirmar que a cultura escolar, dessa escola, não incorpora a cultura pantaneira".

Em contrapartida, Rios (2020, p. 51), em pesquisa realizada em três Escolas das Águas localizadas no Médio e Alto Pantanal corumbaense, afirma que:

Nessas escolas há uma preocupação com o currículo que tem como objetivo aproximar alunos e professores do contexto local, com resgate a cultura em sua mais diversa manifestação, visando a possibilidade de a escola apresentar aos alunos a cultura pantaneira, sua diversidade para além da fauna e da flora.

As diferentes percepções dessas investigações, em momentos e localidades distintos, sobre a incorporação dos elementos socioculturais dos estudantes ribeirinhos e pantaneiros no currículo escolar, podem estar relacionadas à alta rotatividade de professores nas Escolas das Águas (MELO, 2017) e também à preocupação constante da equipe gestora com a formação continuada dos professores que atuam nessas unidades de ensino (RIOS, 2020).

A narrativa da CP1 nos traz algumas pistas sobre os movimentos de construção de uma proposta pedagógica articulada às realidades das comunidades em que se situam as Escolas das Águas: 
A gente ainda está engatinhando no ideal. A gente utiliza a metodologia ativa de aprendizagem, os projetos, os trabalhos em grupos, mas eles ainda são pontuais. A gente ainda não conseguiu fazer com que a equipe docente assuma isso como um compromisso e uma metodologia contínua. Se você ver os nossos portfólios, vai ver várias atividades que entram dentro da metodologia ativa, mas elas são um pouco pontuais. Algumas questões próprias da comunidade são muito delicadas. Posso te citar o exemplo de uma escola em que a gente faz parte do programa do MPT [Ministério Público do Trabalho] na escola, que é contra o trabalho infantil. Então muitas atividades, todo bimestre, são aplicadas dentro desta conscientização da criança e a conscientização da família.

Ao menos dois são os grandes desafios da gestão em relação aos docentes: o primeiro refere-se ao fato de que quase a totalidade tem contrato temporário, o que causa a grande rotatividade; o segundo, que perpassava todo trabalho pedagógico, é o fato de os professores ministrarem componentes curriculares fora da sua formação inicial. Além da contenção de recursos financeiros, a própria dificuldade de seleção de professores dispostos a residirem nas unidades de ensino durante o período letivo parece ser uma barreira constante para a ampliação e qualificação do quadro docente (registro de diário de campo).

Soma-se a isso o fato de que sete, dentre as nove unidades ensino, em 2019 organizavam-se por meio da multisseriação, ampliando as exigências do trabalho pedagógico no cotidiano da sala de aula. Para Rios (2020, p. 116), “as classes multisseriadas são um grande desafio que se apresenta aos professores pois, ao planejar é necessário repensar a escola, as disciplinas, as séries/anos, conteúdos e avaliações".

Sobre a avaliação escolar, o PPP sugeria que esta fosse "realizada de forma contínua, sistemática e integral, ao longo de todo o processo de ensino aprendizagem, observando-se o comportamento do aluno nos domínios cognitivo, afetivo e psicomotor, através de diferentes técnicas e instrumentos" (CORUMBÁ, 2017, p. 15).

Considerando que a equipe gestora das Escolas das Águas (Diretora e Coordenadoras Pedagógicas) concentrava-se na sede urbana do município, o atendimento às demandas do trabalho pedagógico era feito mediante: a) contato por telefone e internet, nas unidades que dispunham desses serviços; b) por visitas periódicas de membros da gestão até as unidades de ensino; c) formações continuadas de docentes ao término de cada bimestre letivo. A Diretora nos informou outra forma de acompanhamento das atividades nas Escolas das Águas:

A gente gesta daqui, mas em cada escola a gente deixa um representante docente para estar atendendo. É ele quem faz os repasses do que está acontecendo, do que está precisando. Então a gente tem esse professor que nos apoia nisso em cada escola, em cada extensão, isso aí nos ajuda bastante. Para tanto, a gente também faz uma escala. A gente não deixa um professor de apoio o ano todo. Então a gente passa a responsabilidade para todos os

RPGE- Revista on line de Política e Gestão Educacional, Araraquara, v. 24, n. esp. 2, p. 1054-1067, set. 2020. e-ISSN:1519-9029 
professores que trabalham nessa escola, por exemplo tenho três professores, um mês é um, outro mês é outro. Então não tem apenas um! A gente fala assim: "todos vocês são responsáveis pela escola, e nós somos responsáveis por todos vocês e por todas as escolas!".

Administrativamente, era realizada uma distribuição de atuação entre as três coordenadoras, cada qual sendo responsabilizada, prioritariamente, por um conjunto de três unidades de ensino. De acordo com a CP2, “embora haja essa divisão, a gente trabalha junto. Quando uma [coordenadora] não pode ir a uma visita, a outra vai. Por isso a gente procura estar alinhada. A gente separa, mas fica junto!”.

Com espaço próprio na sede administrativa urbana das Escolas das Águas, as coordenadoras pedagógicas têm uma rotina intensa de atividades: reuniões com a direção e com a SEMED, atendimentos às famílias, análises de propostas, projetos e materiais pedagógicos, trocas de experiências sobre as visitas às unidades de ensino, encaminhamentos de especificidades de docentes e discentes, organização de formações continuadas, alimentação do sistema de gestão educacional, dentre outras (registro de diário de campo).

A CP2 nos relatou que, com o intuito de atender imediatamente as demandas pedagógicas, “a intenção da SEMED é alocar um coordenador pedagógico por escola, para ficar mais próximo do trabalho do professor!".

Além da Diretora e das Coordenadoras Pedagógicas, atuavam, em 2019, na sede administrativa das Escolas das Águas, uma Secretária, duas Assistentes de Secretaria e um profissional de Serviços Gerais. A Secretaria desempenhava um papel ativo para as matrículas, registros escolares, controle do transporte e da merenda escolar, envio e recebimento de documentos escolares e de pertences pessoais de professores e funcionários alojados nas unidades de ensino, dentre outros (registro de diário de campo).

A equipe gestora, consensualmente, destacou a participação da família e da comunidade nas ações junto às unidades de ensino: "enquanto gestão, ficamos muito felizes porque nós temos uma participação em massa da comunidade. É reunião, família na escola, bingo!” (Diretora); "a participação é intensa! Assim, se propõe uma atividade na escola, porque nós temos a festa da família, festa junina, eles são bem ativos. E independente de festa, de comemorações, eles são pais frequentes" (CP2); "todo final de bimestre tem as reuniões com os pais, porque tem como os professores estarem lá e conversarem com os pais. Esse é o único momento que eles têm de se inteirar dos alunos-filhos deles" (CP3). A CP1 acrescentou ainda que, "em alguns lugares onde a comunidade é mais próxima à escola, a gente começou a fazer a leitura participativa. Então os pais também leem alguns livros de história da nossa biblioteca". 


\section{Considerações finais}

As Escolas das Águas apresentam uma condição singular entre as escolas brasileiras, mesmo entre as demais escolas ribeirinhas de outras regiões do país, devido às condições sociais, culturais, econômicas e naturais que as constituem, no contexto pantaneiro. A despeito das particularidades e diferenças entre as escolas municipais (da área urbana, em assentamentos e ribeirinhas), todas obedecem à determinada organização da gestão. Frente à organização administrativa geral, a gestão das Escolas das Águas tenta construir possibilidades pedagógicas que tornam esses estabelecimentos peculiares em sua organização e seu funcionamento, já que, pelas próprias características fisiográficas, enfrenta situações que se alteram a todo o tempo. Nesse contexto, as decisões de gestão são balizadas por escolhas pedagógicas e políticas de um olhar para a consideração das especificidades regionais, pois a direção e as coordenações pedagógicas reconhecem a importância de atuar junto às comunidades. Nesse cotidiano de decisões e diversidades, a autonomia necessária para a realização do trabalho proposto encontra fortes entraves com as restrições de recursos, agravadas pelas grandes distâncias, pela insuficiência de condições materiais objetivas para um trabalho mais próximo à população local e pela precariedade dos contratos dos docentes, que leva à grande rotatividade desses profissionais. Assim, mesmo com formação para atuar em seus cargos, as gestoras lidam com fortes limitantes para o desenvolvimento de seus trabalhos.

Como descrevem Oliveira e Vasques-Menezes (2018), em interlocução com Vasconcelos (2009), a gestão escolar não exerce "um papel puramente burocráticoadministrativo", mas trata-se "de uma tarefa de articulação, de coordenação e intencionalidade, que, embora suponha os aspectos administrativos, vincula essencialmente o diretor à gestão pedagógica da escola” (p. 881). As escolhas da gestão das Escolas das Águas evidenciam essa relação pedagógica nos cuidados como possibilitam a materialização das políticas educacionais de atenção à diversidade.

No empreendimento dessas tarefas, estão inúmeras instituições públicas e privadas envolvidas: Prefeitura, Ministério Público e organizações não governamentais, como relatado pela CP1 sobre a mobilização para a erradicação do trabalho infantil. Nesse sentido, seriam interessantes pesquisas que adentrassem essas questões, a fim de elucidar como se configuram relações na interface das políticas sociais, a existência de possíveis tensões, as potencialidades para o trabalho pedagógico desenvolvido e, sobretudo as contribuições e suporte à gestão dessas escolas. 
Outro aspecto que merece ser mais explorado refere-se à organização do trabalho pedagógico e do currículo. As populações ribeirinhas e pantaneiras, com seus saberes, culturas, formas de produção material de existência, devem ser instituintes da organização e do desenvolvimento do trabalho pedagógico nas Escolas das Águas. Nessa perspectiva, a imprescindibilidade da participação da família e da comunidade é constitutiva de uma educação a ser construída com e pelos (e não somente para) os sujeitos do campo. Este, no nosso entendimento, é um desafio permanente para a gestão da educação das populações camponesas, das águas, do Pantanal, das florestas.

AGRADECIMENTOS: à CAPES, pelo financiamento da pesquisa.

\section{REFERÊNCIAS}

ABREU, C. M. M. A implantação das escolas ribeirinhas no Pantanal corumbaense: um elemento de enfrentamento ao trabalho infantil. Orientadora: Anamaria Santanada Silva. 2018. 129 f. Dissertação (Mestrado em Educação) - Universidade Federal de Mato Grosso do Sul, Corumbá, 2018. Disponível em: https://ppgecpan.ufms.br/files/2019/01/DissertacaoMestrado-UFMS-CPAN-Cleide-Abreu.pdf. Acesso em: 20 mar. 2020.

CORUMBÁ. E.M.R.E.I. Polo Porto Esperança e Extensões. Projeto Político Pedagógico. Corumbá: Secretaria Municipal de Educação, 2017.

CORUMBÁ. Prefeitura Municipal de Corumbá. Secretaria Municipal de Educação. Lei Ordinária n. 2484/2015, de 26 de junho de 2015. Aprova o Plano Municipal de Educação do município de Corumbá (2015-2025). Corumbá, 2015. Disponível em: http://leis.camaracorumba.ms.gov.br/lei/2739?type_view=consolidada. Acesso em: 10 jun. 2020.

INEP. Sinopse Estatística da Educação Básica. Brasília, 2019. Disponível em: http://portal.inep.gov.br/web/guest/sinopses-estatisticas-da-educacao-basica. Acesso: 29 mar. 2020.

KASSAR, M. C. M. et al. Educação especial na perspectiva da educação inclusiva em um município do Mato Grosso do Sul. Cadernos CEDES, Campinas, v. 38, n. 106, p. 299-313, set./dez. 2018.

MELO, R. Z. Jogar e brincar de crianças pantaneiras: um estudo em uma "escola das águas”. 2017. 147 f. Tese (Doutorado em Educação) - Pontifícia Universidade Católica do Rio de Janeiro, Rio de Janeiro, 2017.

OLIVEIRA, F. R. Os nexos da educação integral no Pantanal de Corumbá-MS: práticas de ensino na escola Jatobazinho. Orientadora: Claudia Araújo de Lima. 2018. $107 \mathrm{f}$. Dissertação (Mestrado em Educação) - Universidade Federal de Mato Grosso do Sul, Corumbá, 2018. Disponível me: 
https://ppgecpan.ufms.br/files/2019/02/DISSERTA\%C3\%87\%C3\%83O-

Francisca_Oliveira.pdf. Acesso em: 20 mar. 2020.

OLIVEIRA, I. C.; VASQUES-MENEZES, I. Revisão de literatura: o conceito de gestão escolar. Cadernos de Pesquisa, São Paulo, v. 48, n. 169, p. 876-900, set. 2018.

PNUD. IPEA. FJP. Atlas do desenvolvimento humano no Brasil. 2013. Disponível em: http://atlasbrasil.org.br/2013/pt/perfil_m/corumba_ms. Acesso: 29 mar. 2020.

RICHARDSON, R. J. Pesquisa social: métodos e técnicas. 4. ed. São Paulo: Atlas, 2017.

RIOS, E. C. A prática pedagógica do professor de Educação Física nas escolas ribeirinhas do Pantanal Sul-mato-grossense. 2020. 147 f. Dissertação (Mestrado em Educação) - Universidade Federal de Mato Grosso do Sul, Corumbá, 2020.

VASCONCELLOS, C. S. Coordenação do trabalho pedagógico: do projeto políticopedagógico ao cotidiano da sala de aula. 11. ed. São Paulo: Libertad, 2009.

ZERLOTTI, P. H. Os saberes locais dos alunos sobre o ambiente natural e suas implicações no currículo escolar: um estudo na escola das águas - extensão São Lourenço, no Pantanal de Mato Grosso do Sul. Orientadora: Maria Aparecida de Souza Perrelli. 2014. 128 f. Dissertação (Mestrado em Educação) - Universidade Católica Dom Bosco, Campo Grande, 2014. Disponível em: https://site.ucdb.br/public/md-dissertacoes/14030-patriciazerlotti.pdf. Acesso em: 20 mar. 2020.

\section{Como referenciar este artigo}

NOZU, W. C. S.; REBELO, A. S.; KASSAR, M. C. M. Desafios da gestão nas escolas das aguas. Revista on line de Política e Gestão Educacional, Araraquara, v. 24, n. esp. 2, p. 10541067, set. 2020. e-ISSN:1519-9029. DOI: https://doi.org/10.22633/rpge.v24iesp2.14331

Submetido em: 30/04/2020

Revisões requeridas em: 26/06/2020

Aprovado em: 30/07/2020

Publicado em: 30/09/2020 